\title{
Nafion-coated $\mathrm{LiNi}_{0.80} \mathrm{Co}_{0.15} \mathrm{Al}_{0.05} \mathrm{O}_{2}$ (NCA) cathode preparation and its influence on the Li-ion battery cycle performance
}

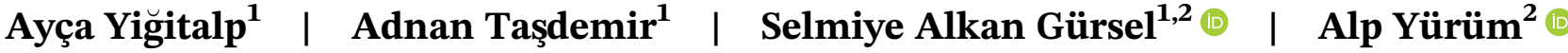

\begin{abstract}
${ }^{1}$ Faculty of Engineering and Natural Sciences, Sabanci University, Istanbul, Turkey

${ }^{2}$ Nanotechnology Research \& Application Center (SUNUM), Sabanci University, Istanbul, Turkey

\section{Correspondence}

Alp Yürüm, Nanotechnology Research \& Application Center (SUNUM), Sabanci University, Tuzla, Istanbul 34956, Turkey. Email: ayurum@sabanciuniv.edu
\end{abstract}

\begin{abstract}
One of the main problems of $\mathrm{LiNi}_{0.80} \mathrm{Co}_{0.15} \mathrm{Al}_{0.05} \mathrm{O}_{2}$ (NCA) materials is the side reactions occurring during battery cycling. These side reactions result in capacity fading, which in turn decreases the life span of the battery. Conventionally, for nickel-rich cathodes, an inorganic layer is used as a protective layer. Applying these layers may require additional complicated steps. To overcome this problem, we focused on coating the NCA electrode with a polymeric ion conductive layer that can easily be applied. For this purpose, using an ionconductive polymer is a novel approach. We used Nafion as the protective layer on NCA electrodes. While the Nafion layer can protect the surface against the side reactions, it does not prevent the $\mathrm{Li}^{+}$ion flow. Following this purpose, we synthesized NCA by a modified co-precipitation method followed by sintering at $750^{\circ} \mathrm{C}$. After the preparation of the NCA cathodes, we coated the surfaces with a more straightforward drip coating. The Nafion-coated electrodes delivered a superior electrochemical performance with $100 \%$ of discharge capacity retention even after 100 cycles at $0.1 \mathrm{C}$. The electrochemical impedance spectroscopy revealed that the Nafion coating could effectively prevent passive layer formation, which causes capacity fading.

K E Y W O R D S

cathode, Li-ion, Nafion, NCA, protective layer
\end{abstract}

\section{1 | INTRODUCTION}

The advance of energy storage and conversion technology is one of the leading research topics in today's world. In this regard, lithium-ion batteries with their higher energy density, charge, discharge capacities, and longer cycle life have generated significant interest in portable electronics and electric cars. Although these criteria are much more tolerable for the materials that are used in anode electrodes, cathode electrodes always require a certain threshold in terms of discharge capacity and energy density, which tend to become as limiting and determining electrode. ${ }^{1,2}$ Even so, different cathode materials and synthesis routes may be used to build up commercial LIBs. ${ }^{3}$ In those cathode materials, many of the LIBs utilize Corich cathodes as they may relatively provide higher discharge capacity and excellent electrochemical cycling. ${ }^{4,5}$ Despite their superb specifications, cobalt cost is a huge barrier, and the industry and academia had tried to replace cobalt with safer and more affordable elements. ${ }^{2,6,7}$ Nickel-rich layered cathodes are the solution to this problem since they provide high reversible capacity and reasonable costs. Some of the materials are layered oxides such as lithium nickel manganese cobalt 
oxides (NMC) or lithium nickel cobalt oxides (NCO) ${ }^{8,9}$ Within that Ni-rich cathode family, $\mathrm{LiNi}_{0.80} \mathrm{Co}_{0.15} \mathrm{Al}_{0.05} \mathrm{O}_{2}$ (NCA) is a highly promising candidate, particularly for utilizing in electric vehicles. Their delithiated phase creates a thermally stable environment, which, in turn, reduces the safety concerns. ${ }^{4,10}$ Moreover, most of the theoretical capacity of NCA $(276.5 \mathrm{mAh} / \mathrm{g})$ effectively participate in charge/discharge cycles with the range of 3.2 to $4.3 \mathrm{~V}$, which back as high discharge capacity. ${ }^{10,11}$

Synthesizing NCA may be achieved by various methods. ${ }^{12,13}$ Purwanto et al have summarized in detail various synthesis techniques of NCA cathode active material for LIBs. These methods with different synthesis characteristics result in differences in particle sizes. ${ }^{14}$ In this regard, the literature itself provides several examples for different synthesis characteristics depending on the synthesis routes. ${ }^{15}$ For instance, solid-state reactions allow a higher quantity of NCA powder but require higher energy. ${ }^{16-18}$ On the other hand, the modified solgel method creates much finer particles within the structure, thus enhances electrochemical activity. While in the spray pyrolysis, the particles are not stable during sintering at elevated temperatures. Single co-precipitation method can result in powders with crystalized layered structures and a more isotropic shape of NCA. ${ }^{19,20}$

Despite its extensive range of production methods and its excellent discharge capacity, the most significant drawbacks of NCA cathodes are the side-reactions that occur during the cycling. These reactions limit the cycling performance, which in turn decreases the life span of the electrode. ${ }^{16,20,21}$ These side-reactions are due to the highly active transition metal at the charged-state and reacting with the electrolyte. In addition to that, during the charge/discharge cycles, the microcracks naturally present in the NCA particles propagate with expansion/contraction. This phenomenon creates new surfaces to react with the electrolyte. To eliminate these side reactions, scientists have tried many different surface modifications applied to the cathodes. ${ }^{22-24}$ For instance, $\alpha-\mathrm{MoO}_{3}$ particles are used on layered cathodes of $\mathrm{Li}_{0.20} \mathrm{Mn}_{0.54} \mathrm{Ni}_{0.13} \mathrm{Co}_{0.13} \mathrm{O}_{2}$, and it is reported that a thin layer of $\alpha-\mathrm{MoO}_{3}$ particles enhanced the electrochemical performances in charge and discharge tests by preventing the side-reactions. ${ }^{25} \mathrm{He}$ et al demonstrate that a protective layer like Mn-rich oxide on the NCA surface can protect the material, suppress the phase changes, and enhance the performance of the electrode. ${ }^{26-28}$

Another example is using a nano-scale carbon coating on the NCA cathode as the layer provides much higher diffusivity for Li-ions and decreases the mechanical stress, which in turn provides a significant recovery on the discharge capacity. ${ }^{2,4,18,19,21,29,30}$ Wrapping the Nirich cathode with lithium lanthanum titanium oxide
(LLTO) inorganic film is a different example of surface modification type. Kim et al claim that it prevents the side reactions of nickel-rich cathodes, thus remedy on the capacity. ${ }^{31}$ The readers should keep in mind that all these surface modifications mentioned above use inorganic coatings that are rather complex and require a certain amount of energy to implement into practice.

Herein, our motivation is to minimize the side reactions on the NCA cathode and achieve a highly stable electrochemical performance by applying a simple coating technique. In this technique, an ion-conducting polymer is simply drip coated on to the cathode. This coating, while creating a very thin barrier between the electrolyte and the electrode, prevents the side-reactions and microcrack propagations. In line with this goal, the NCA cathode was developed by first a modified co-precipitation method that provided a lot of smaller and dispersed powders. Then a surface modification was applied with a Nafion coating on the prepared NCA cathode powders. In the literature, there are studies with electronconducting polymers as a coating. However, to the best of our knowledge, a surface modification, where an ionconducting polymeric protective coating, has not been reported on any Li-ion battery cathode. Our purpose for using the Nafion coating was to help to create a stable electrochemical performance under long charge/discharge cycles by preventing the side reactions and disintegration due to microcrack propagations. The microcracks expose more of the surface to the electrolyte, thus increases the side-reactions with cycling and deteriorates the cathode. In the study, the results are comparatively shown and discussed for both pristine NCA and Nafion-coated NCA.

\section{2 | EXPERIMENTAL PROCEDURE}

\section{1 | Material synthesis}

All the chemicals were purchased from Sigma-Aldrich, and they were used without further purification. To synthesize NCA cathode active material, $\mathrm{Co}\left(\mathrm{CH}_{3} \mathrm{CO}_{2}\right)_{2} \cdot 4 \mathrm{H}_{2} \mathrm{O}, \mathrm{Ni}\left(\mathrm{CH}_{3} \mathrm{CO}_{2}\right)_{2} \cdot 4 \quad \mathrm{H}_{2} \mathrm{O}, \mathrm{AlCl}_{3}$, and $\mathrm{C}_{2} \mathrm{H}_{2} \mathrm{O}_{4}$ were used as the starting materials. They were completely dissolved in $200 \mathrm{~mL}$ of distilled water with a molar ratio of Ni:Co:Al $=80: 15: 5$. After that, $\mathrm{C}_{2} \mathrm{H}_{2} \mathrm{O}_{4}$ was added then $10 \mathrm{~mL}$ of $\mathrm{NH}_{3}(30 \%)$ was poured to the solution for precipitation. The solution was then continuously stirred for 2 hours. The mixed solution was placed in an on-oil bath at $90^{\circ} \mathrm{C}$ for overnight to ensure a complete chemical reaction. The obtained $(\mathrm{NiCoAl}) \mathrm{C}_{2} \mathrm{O}_{4}$ powders were then calcined at $500^{\circ} \mathrm{C}$ for 8 hours in an air atmosphere. Sintered powders were mixed with $\mathrm{C}_{2} \mathrm{H}_{3} \mathrm{LiO}_{2}$. 
The amount was 1.1 times the stoichiometric Li required in the structure. After calcinated powders were analyzed in TGA, the best calcination temperature was determined as $750^{\circ} \mathrm{C}$. The final sintering was applied accordingly in an air atmosphere for 12 hours to obtain a black LiN$\mathrm{i}_{0.80} \mathrm{Co}_{0.15} \mathrm{Al}_{0 \cdot 05} \mathrm{O}_{2}$ (NCA) powder.

Powder characterization of the NCA was done via XRD and SEM. XRD patterns for NCA were analyzed in a Bruker D2 Phaser that used $\mathrm{CuK} \alpha$ radiation with $1.54 \AA$ wavelength to characterize phase composition and crystal structure of synthesized materials. The powder X-ray diffraction measurements were collected from $5^{\circ}$ to $90^{\circ}$ and $2 \theta$ with a step size of $0.02^{\circ}$ and a step speed of $0.5^{\circ} / \mathrm{min}$. The morphology of the obtained electrode powder and the surface of the electrodes that were pristine and Nafion modified were examined in a Zeiss LEO Supra 35VP SEMFEG scanning electron microscope.

\subsection{Preparing the NCA cathode slurry}

To prepare the cathode slurry, we took polyvinylidene difluoride (PVDF, Sigma-Aldrich), carbon black (CB, Sigma-Aldrich), and NCA powder in the 5:25:70 proportions, respectively. After the ingredients were mortared, they were mixed NMP ( $N$-Methyl-2-pyrrolidone, SigmaAldrich) to obtain a uniform and viscous slurry. After the slurry was stirred overnight, we coated the slurry on to the current collectors. The coated film was then dried at $120^{\circ} \mathrm{C}$ overnight in a vacuum oven. As a final step, the electrodes were immediately taken out from the oven hot-pressed at $120^{\circ} \mathrm{C}$ for 2 minutes and put into the glovebox.

\section{3 | Coating NCA cathode with Nafion}

Nafion, which is a sulfonated tetrafluoroethylene-based fluoropolymer-copolymer, is frequently used in energy conversion applications, primarily in proton exchange membrane fuel cells as a proton conductor due to its high chemical stability as well as superior proton conductivity. ${ }^{32}$ Here in this research, the reason for using Nafion is its excellent ionic conductivity, high chemical stability, and serving as a protective layer on the NCA cathode. With these properties, Nafion can help to eliminate the propagation of microcracks by covering the NCA particles and inhibit the surface reactions. As a result, the protective layer helps to achieve a stable cyclability. Nafion (Fuel Cell Earth, 15\% wt) was diluted in water by $30 \%$. A drip coating method is then applied with a $100-\mu$ l pipette from $2 \mathrm{~cm}$ to the surface of the NCA electrode without touching the surface. And lastly, they were dried overnight at $60^{\circ} \mathrm{C}$ in a vacuum oven.

\subsection{Assembling the coin cells}

The electrodes were assembled in CR2032 coin cells in a glovebox for electrochemical characterizations. Li chips were used as the counter electrodes. $1 \mathrm{M} \mathrm{LiPF}_{6}$ solution in ethylene carbonate (EC)/diethyl carbonate (DEC) (1:1 $\mathrm{vol} / \mathrm{vol}$, Sigma-Aldrich) was used as the electrolyte, and a polypropylene separator (Celgard) was used as the separator.

The cyclic voltammograms were recorded between 3.0 and $4.3 \mathrm{~V} \mathrm{(vs} \mathrm{Li} / \mathrm{Li}^{+}$) at a sweep rate of $0.1 \mathrm{mV} \mathrm{s}^{-1}$. For the cycling performance, the coin-cells were galvanostatically charged and discharged at different current rates of $0.1 \mathrm{C}, 0.5 \mathrm{C}$, and $1 \mathrm{C}$ for 100 cycles in the voltage range of 3.3 and $4.2 \mathrm{~V}$. For the rate capability performance, the current was alternated from $0.1 \mathrm{C}, 0.5 \mathrm{C}$, $1 \mathrm{C}, 2 \mathrm{C}$, and $0.1 \mathrm{C}$ for 40 cycles (between 3.3 and $4.2 \mathrm{~V}$ ). Electrochemical impedance spectroscopy (EIS) responses were obtained between the frequency range of $1 \mathrm{mHz}$ and $-1 \mathrm{MHz}$ with an $\mathrm{AC}$ amplitude of $5 \mathrm{mV}$. All of the electrochemical tests were carried out in a Princeton Applied Research PARSTAT MC system.

\section{3 | RESULTS AND DISCUSSION}

\section{1 | Powder characterization}

We show the XRD pattern of the NCA powder in Figure 1A. As indicated in the figure, all of the diffraction peaks of NCA is indexed to a fine layered $\alpha-\mathrm{NaFeO}_{2}$ structure $(R \overline{3} \mathrm{~m})$ (JCPDS Card \#87-1562). ${ }^{33}$ The peaks at $18.8,36.7,38.2,38.5,44.5,48.7,58.8,64.6,65.1^{\circ}$ were indexed to (003), (101), (006), (102), (104), (105), (107), (018), and (110) planes, respectively. ${ }^{34}$ These peaks verify that the material has a $\mathrm{LiNiO}_{2}$ structure. We did not observe peaks other than $\mathrm{LiNiO}_{2}$ 's. It confirms that Co and $\mathrm{Al}$ atoms are properly incorporated into the lattice, meaning that a layered $\mathrm{O}_{3}$ rhombohedral NCA material was successfully synthesized. ${ }^{35,36}$ In these materials, apparent double peaks of (006)/(102) and (018)/(110) should be seen, which is the observed case for this material (Figure 1B,C). NCA based materials with a good hexagonal structure should have a low-intensity ratio of $\mathrm{I}_{(006)} /\left(\mathrm{I}_{(101)}+\mathrm{I}_{(102))}\right){ }^{37}$ We calculated this ratio to be 0.0907 for the NCA in this study. A value that low is considered to be more than sufficient since commercial NCA can have a factor of about $0.13 .^{38,39}$ We present the XRD pattern of the Nafion-coated NCA electrode in Figure S1. 
In this pattern, there are additional peaks due to the carbon black, PVDF and the current collector. The NCA peaks became broader due to conformal thin film on the crystal particles. However, the pattern shows that the NCA structure is conserved.

For layered $\mathrm{LiNiO}_{2}$ type cathodes, cation mixing is a crucial fact that limits the cathode performance. The extent of cation mixing in the structure can be estimated from the intensity ratio of $\mathrm{I}_{(003)} / \mathrm{I}_{(104)}{ }^{34}$ This value should be higher than 1.2 to have a low cation mixing. The ratio calculated for the NCA powder synthesized in this study is 1.9 , which is attributed to a low cation mixing. At higher sintering temperatures like $850-950^{\circ} \mathrm{C}$, a high value of 2.1 can be obtained. ${ }^{40,41}$ However, at these conditions, much bigger particles form, and this would adversely affect the polymer coating's effectivity.

We performed the SEM characterization of NCA to understand the morphology and detailed structure of the sintered particles. Figure 2 shows the agglomerated polyhedral particles of NCA sintered at $750^{\circ} \mathrm{C}$. Their average particle size was $240 \mathrm{~nm}$. While particles with threefold rotation symmetry can be seen in Figure 2B, their particle size varies between 40 and $510 \mathrm{~nm}$ (Figure 3). According to the XRD analysis, the average crystallite size of the particles is $107 \mathrm{~nm}$, which suggests that most of the powder consists of fused polycrystalline particles (about $80 \%$ ).
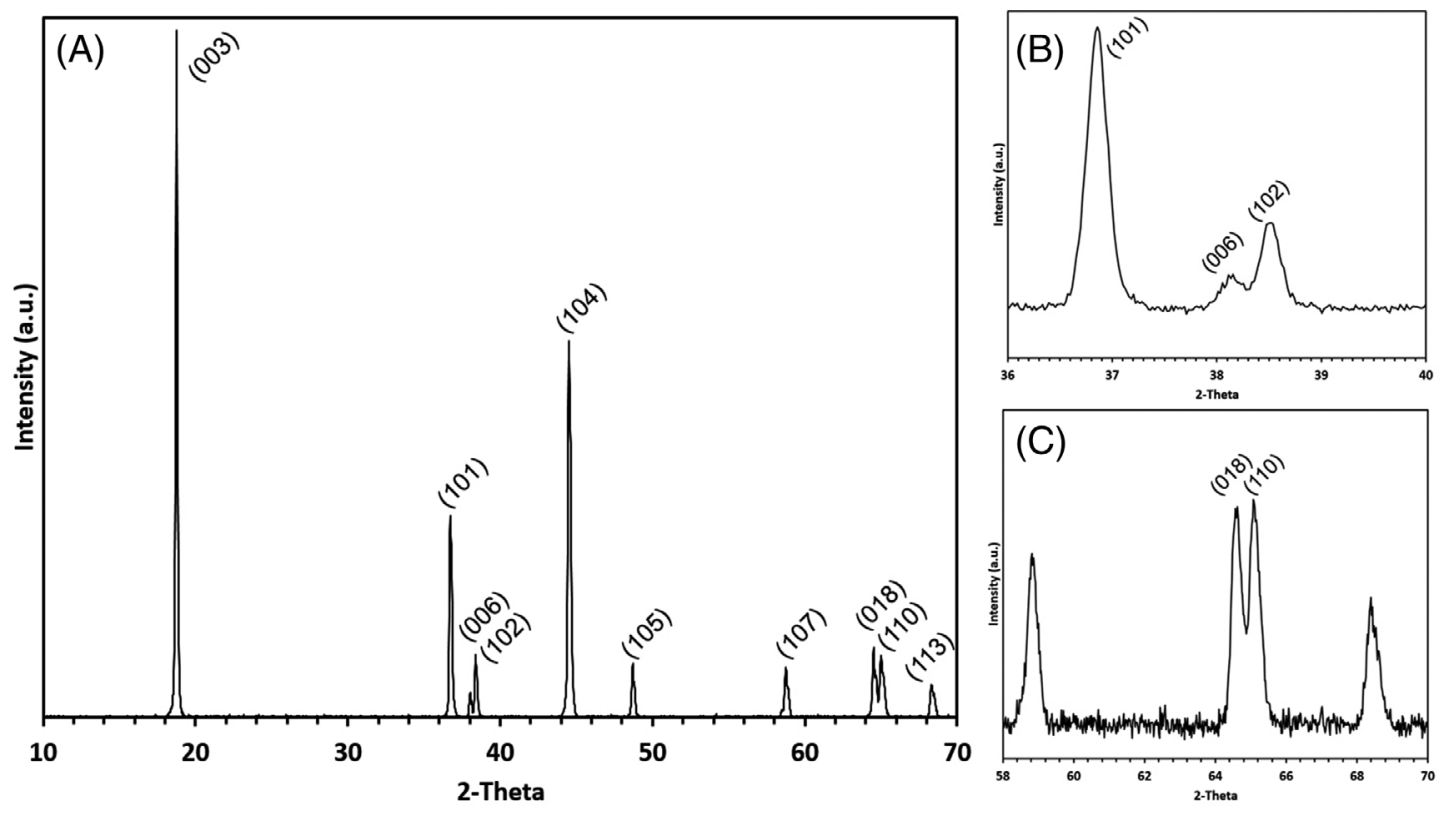

F I G URE 1 XRD pattern of the NCA powder sintered at $750^{\circ} \mathrm{C}$

(A)

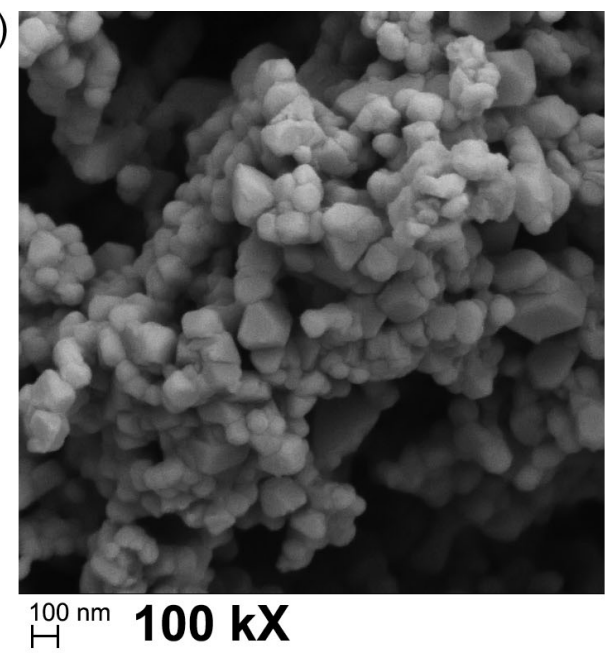

(B)

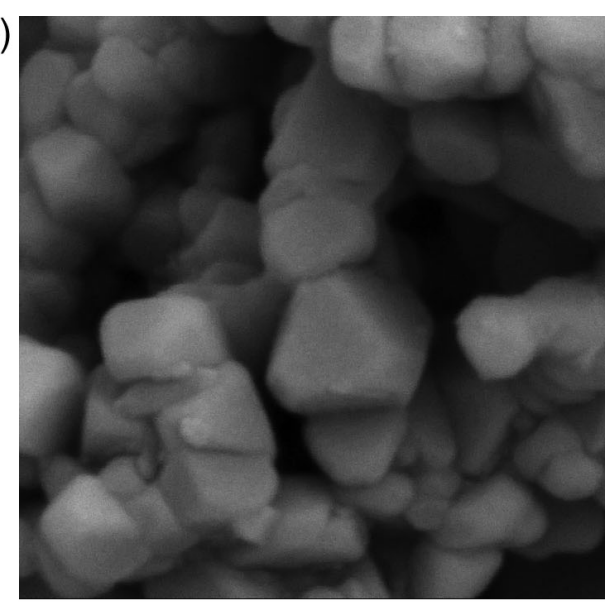

$\stackrel{100 \mathrm{~nm}}{\longmapsto} 300 \mathrm{kX}$

F I G U R E 2 SEM micrographs of NCA sintered at $750^{\circ} \mathrm{C}$. Images at, A, lower, and, B, higher magnifications 
In the NCA structure, it is difficult to oxidize all $\mathrm{Ni}^{2+}$ to $\mathrm{Ni}^{3+.42} \mathrm{Ni}^{2+}$ occupies a certain amount of $\mathrm{Ni}^{3+}$ sites, but these ions move to the $\mathrm{Li}^{+}$layer to conserve charge in the structure (cation mixing). Cation mixing is an unwanted situation and should be minimized during the synthesis. Due to that reason, NCA requires high sintering temperatures. Although there are several methods to synthesize NCA and similar materials, the most common ones are solid-state synthesis and solutionbased synthesis. In solid-state synthesis, all the solid reactants are mechanically mixed and heat to high temperatures like $725^{\circ} \mathrm{C}$ in a furnace under an $\mathrm{O}_{2}$ environment. ${ }^{43,44}$ Since the materials are already in solid form, the final product tends to be large. Particles with dimensions ranging from 1 to $10 \mu \mathrm{m}$ sinters to form large clumps of 10 to $200 \mu \mathrm{m}$. When the particle size is that big, it is more prone to cracking. ${ }^{45}$ Due to cracking and inhomogeneous metal distribution in the crystal, the cathode can lose about $20 \%$ of its capacity after only 20 cycles. $^{43}$

Solution-based synthesis facilitates better mixing at the atomic level. In this method, dissolved precursors are precipitated or gelated and after that heat-treated in a furnace. These methods produce finer particles with better cycling stability. ${ }^{46-48}$ But since the particles are smaller, they are more reactive and tend to react with atmospheric $\mathrm{CO}_{2}$ to form a $\mathrm{Li}_{2} \mathrm{CO}_{3}$ layer. ${ }^{49}$ This layer prevents ion and electron mobility for the NCA particles. In this study, although the particles are at the nanoscale, XRD characterization did not show any $\mathrm{Li}_{2} \mathrm{CO}_{3}$ layer due to storing the electrodes in a glovebox.

For an active material, nanomaterials with a porous structure are crucial for effective Li-ion diffusion.

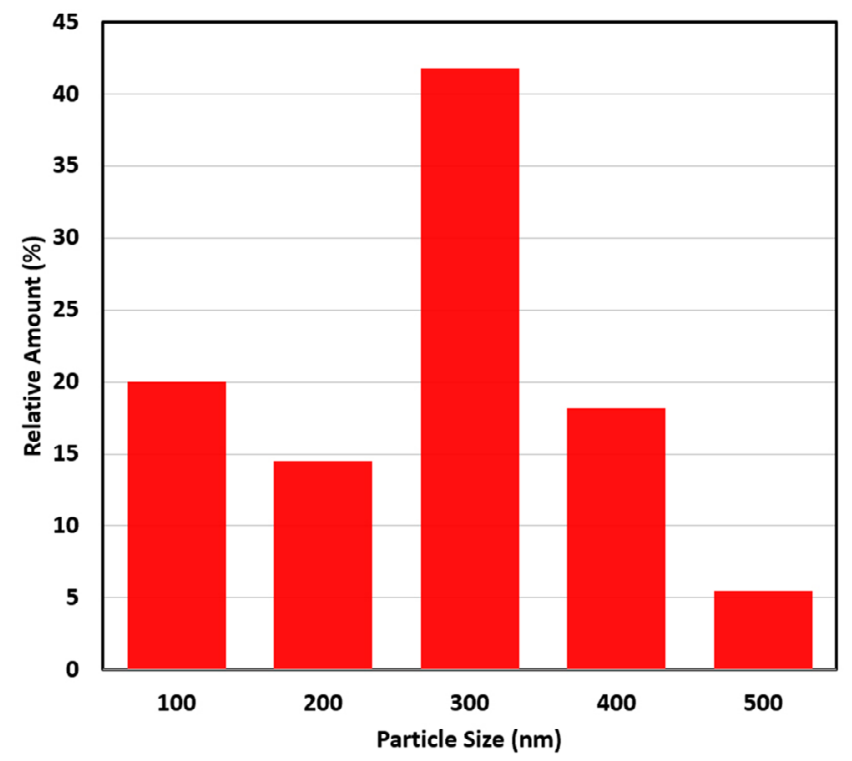

F I G URE 3 Particle size distribution of NCA powder
Moreover, the porous structure can resist the volume expansion more efficiently. Among the methods to obtain a porous structure, co-precipitation is probably the most suitable for industrial applications. In the literature, oxalic acid was used as a precipitating agent for various cathode materials like $\mathrm{LiNi}_{0.5} \mathrm{Mn}_{0.5} \mathrm{O}_{4}$ and $\mathrm{Li}_{1.2} \mathrm{~N}$ $\mathrm{i}_{0.13} \mathrm{Co}_{0.13} \mathrm{Mn}_{0.54} \mathrm{O}_{2} .{ }^{50,51}$ However, to the best of our knowledge, it has not been used for NCA synthesis before. As can be seen from Figure 2, the particle structure is porous, and its open structure is more suitable for a polymer coating.

In addition to the powder characterization, we took a cross-sectional SEM image of the Nafion-coated NCA electrode before the cycling tests (Figure 4 and S1). The SEM image clearly shows the Nafion nano-thin transparent film on the NCA electrode. Moreover, Nafion completely coats the electrode surface. It also reveals the encapsulation of NCA particles on the surface. Layered cathode materials like NCA needs a coating layer that suppresses the unwanted reactions between the cathode surface and electrolyte. In addition to that, since these materials can experience cracking, the coating also creates a barrier against the microcracks. ${ }^{52,53}$ The coating on the surface should be as uniform as possible. However, more importantly, these layers should not prevent lithium-ion conduction. ${ }^{54}$

When the literature is examined, depending on the base material, various coatings can be seen, but all of these coatings are inorganic materials like $\mathrm{SiO}_{2}, \mathrm{Al}_{2} \mathrm{O}_{3}$, $\mathrm{TiO}_{2}$, and $\mathrm{ZnO} .^{55,56}$ In addition to that, most of them are not ion-conducting materials. A no ion-conducting layer means that while the coating prevents the unwanted surface reactions, it also creates an additional resistance for

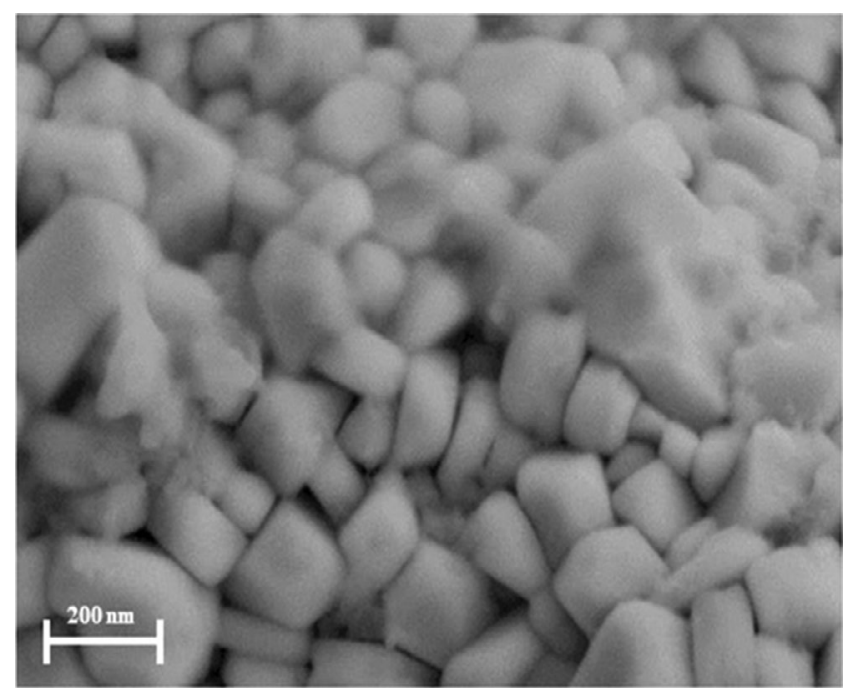

F I G U RE 4 Cross-sectional view of Nafion-coated NCA cathode 
ion mobility. To coat the cathode active material with an oxide, usually, the oxide precursor is mixed with the cathode active material and calcined/sintered. Cho et al prepared a $\mathrm{SiO}_{2}$-coated NCA by mixing the NCA powder with $\mathrm{SiO}_{2}$ nanoparticles and sintered the material at $700^{\circ} \mathrm{C}^{57}$ After the sintering process, NCA agglomerates of about $6 \mu \mathrm{m}$ were coated with a $500 \mathrm{~nm} \mathrm{SiO}_{2}$ layer. Although the protective layer can protect the material, it slows down the $\mathrm{Li}^{+}$migration at high current densities. A thin layer of oxide coating can be achieved with more complicated techniques like atomic layer deposition (ALD). Mohanty et al coated NCA powders with $\mathrm{Al}_{2} \mathrm{O}_{3}$ and $\mathrm{TiO}_{2}$ using an ALD technique. ${ }^{58}$ They achieved a coating thickness of about $10 \mathrm{~nm}$. Interestingly they observed that while the $\mathrm{Al}_{2} \mathrm{O}_{3}$ layer protects the material, $\mathrm{TiO}_{2}$ coating could not stabilize the surface.

NCA can also be coated with active materials that facilitate the Li-ion movement. Srur-Lavi et al coated NCA electrodes with ALD. ${ }^{59}$ They obtained $2 \mathrm{~nm}$ thick $\mathrm{LiAlO}_{2}$ layers, and the capacity fading was three times better than the uncoated sample. The study shows the importance of the coating both as a protective layer and Li-ion migration medium. In the current study, we showed that a conformal nano-sized ion-conducting polymeric coating could be easily applied to the electrode surface. It should also be noted that usually, the cathode active materials are coated with a protective layer, and then an electrode is prepared. ${ }^{60}$ However, directly covering the electrode makes the process much simpler and less energy-consuming.

\section{2 | Electrochemical characterizations}

To understand the electrochemical activity of the electrodes, first, a cyclic voltammetry test was performed. As shown in Figure 5, there are three redox pairs for both pristine and Nafion-coated electrodes. This result is consistent with the cathode materials that have a $\mathrm{LiNiO}_{2}$ (LNO) structure. ${ }^{43,61,62}$ These peaks correspond to the phase transitions from hexagonal (H1) to monoclinic (M) $(3.78 \mathrm{~V})$, monoclinic $(\mathrm{M})$ to a second hexagonal structure $(\mathrm{H} 2)(4.03 \mathrm{~V})$ and finally from the second hexagonal structure (H2) to a third one (H3) $(4.24 \mathrm{~V})$ during the reduction. During the oxidation, the phase transitions occur in the opposite direction $(4.15 \mathrm{~V} \rightarrow 3.93 \mathrm{~V} \rightarrow 3.66 \mathrm{~V})$. Both of the electrodes showed the same peaks with no distinct shifts. These results show that the Nafion coating on the NCA electrode does not adversely interfere with the lithiation/delithiation process, and both of the electrodes have similar electrochemical activities. When the NCA cyclic voltammograms in the literature are examined, it can be seen that when the particles are porous, the $\mathrm{H} 1 \rightarrow \mathrm{M}$ and $\mathrm{M} \rightarrow \mathrm{H} 2$ transition peaks are more distinct. $^{37,63,64}$ However, with dense particles, these peaks merge and observed as a single peak. In this study, the NCA structure is porous, as can be seen from the SEM images (Figure 2), and similar to the literature, each transition is visible in the $\mathrm{CV}$ curves.

We present the initial charge/discharge profiles of pristine and Nafion-coated NCA electrodes in Figure 6. Although the electrodes had similar electrochemical activities in the cyclic voltammograms, they showed significantly different profiles. Nafion-coated NCA electrode, at the first cycle, delivered discharge/charge capacities of 202 and $182 \mathrm{mAh} / \mathrm{g}$ (91\% efficiency),

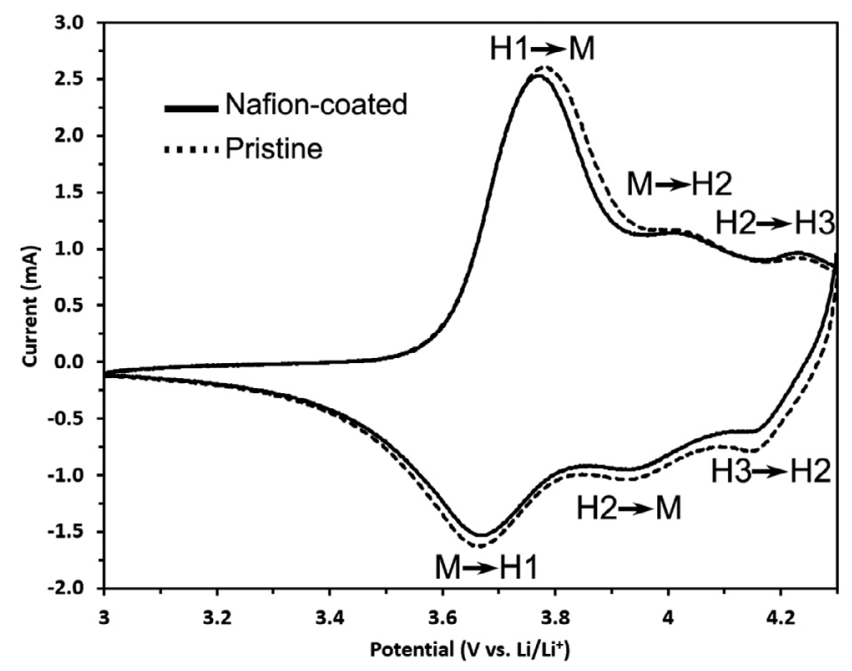

F I G U RE 5 Cyclic voltammograms of pristine (dashed-line) and Nafion-coated (solid-line) NCA electrodes

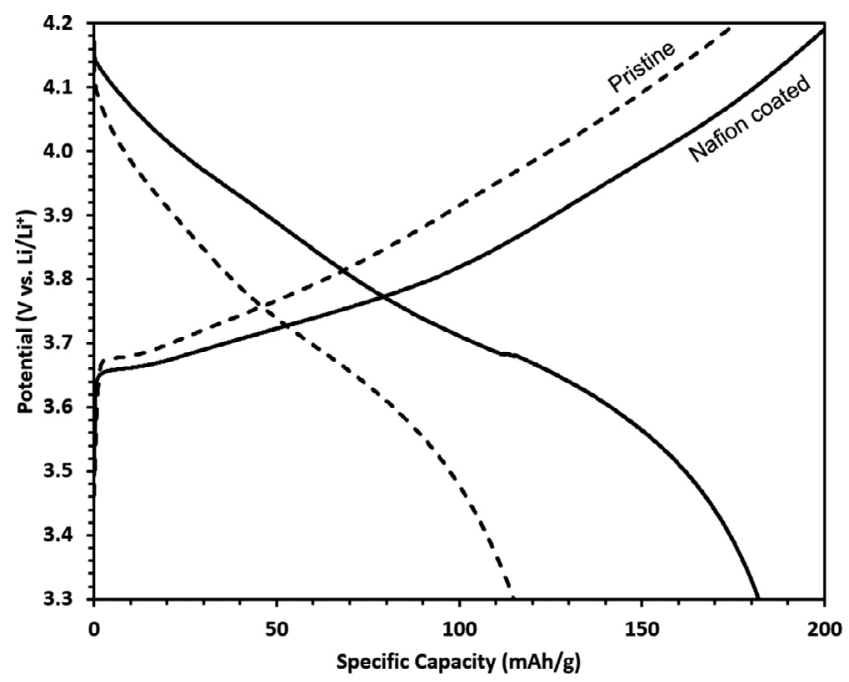

FI G URE 6 Charge/discharge profiles of pristine (dashed line) and Nafion-coated (solid line) NCA electrodes (first cycle at 0.1C) 
respectively, at $0.1 \mathrm{C}$. On the other hand, the pristine electrode, under similar conditions, had discharge/charge capacities of 176 and $115 \mathrm{mAh} / \mathrm{g}$ (65\% efficiency), respectively. This significant difference suggests that the pristine electrode is vulnerable to unwanted reactions, which causes a drop in capacity. Without a protective layer, the pristine cathode deteriorated immediately in the first cycle and showed a capacity lower than the theoretical values. Nevertheless, both of the electrodes showed a typical NCA profile. ${ }^{65-67}$

During the lithiation/delithiation of cathodes, Li-rich and Li-deficient regions occur in the same particle. These regions can create coherency strains, and the particle needs an overpotential to be delithiated. ${ }^{45,68}$ For NCA, such an overpotential can be observed when the structure is not oxidated enough, and there is a cation mixing. ${ }^{63}$ As discussed in the powder diffraction section, we did not expect to have cation mixing, and the charge/discharge profile also supports that.

Figure 7 shows the cyclic performance of pristine and Nafion-coated NCA electrodes. At 0.1C, the Nafioncoated electrode showed capacities close to reported values and, after 100 cycles, retained $100 \%$ of its capacity. Although the pristine electrode's capacity retention at 0.1C was similar, the capacity was lower due to the already degraded surface. ${ }^{69-72}$ With increasing current rates, the specific capacities of both electrodes decreased. At $0.5 \mathrm{C}$ and $1 \mathrm{C}$, the Nafion-coated electrodes showed a steady capacity until about the 20th cycle. After that, the specific capacity started to decline, and the capacity retention was $88 \%$ at the 100th cycle. The pristine electrodes, at higher current rates, performed more erratically. The cycling results show that the Nafion coating effectively improved the performance of the electrodes.
When the surface is not coated, it is prone to surface reactions, which yields non-active phases and creates extra resistance for ions to flow. ${ }^{73}$

Depending on the synthesis procedure, uncoated NCA can have varying capacity retention. In one study, while an NCA without a coating can have $56 \%$ of retention after 40 cycles at $1 \mathrm{C},{ }^{74}$ after $\mathrm{Co}_{3}\left(\mathrm{PO}_{4}\right)_{2}$ coating, the retention increases to $86 \%$. In another study, NCA's retention was increased from $53 \%$ to $75 \%$ with $\mathrm{Ni}_{3}\left(\mathrm{PO}_{4}\right)_{2}$ coating. ${ }^{75}$ These coatings are active materials that do not create resistance for ion flow. When the coating is a nonactive material like $\mathrm{TiO}_{2}$, the retention after the coating can be as low as $63.5 \%{ }^{76}$ The Nafion structure lets the flow of Li ions and prevents surface reactions. This prevention results in more steady cycling performance and high capacity retention.

Rate capability tests are essential to understand the behavior of the battery under changing current densities. We show the rate performance of pristine and Nafioncoated NCA cathodes in Figure 8. The Nafion-coated electrode performed much more stable with higher capacities due to the protective layer on the surface. The electrode delivered discharge capacities of 182, 154, 136 , and $102 \mathrm{mAh} / \mathrm{g}$ at the end of $0.1 \mathrm{C}, 0.5 \mathrm{C}, 1 \mathrm{C}$, and $2 \mathrm{C}$ cycles, respectively. Moreover, the Nafion-coated electrode recovered $100 \%$ of its capacity after reaching back to $0.1 \mathrm{C}$. Although both electrodes demonstrated stable discharge characteristics under different current densities, the Nafion-coated NCA electrode showed a much better reversible capacity than the pristine NCA. The observed capacity fade of the pristine electrode was $5 \%$ at $0.1 \mathrm{C}$. We may attribute this to the passive layers formed on the pristine electrode, which has low ionic and electronic conductivity. ${ }^{77,78}$
(A)

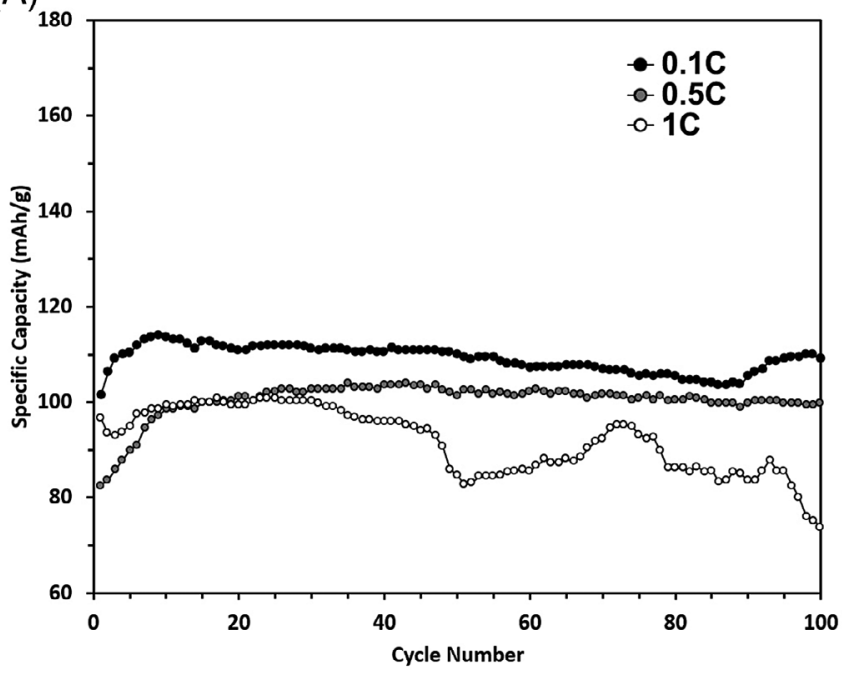

(B)

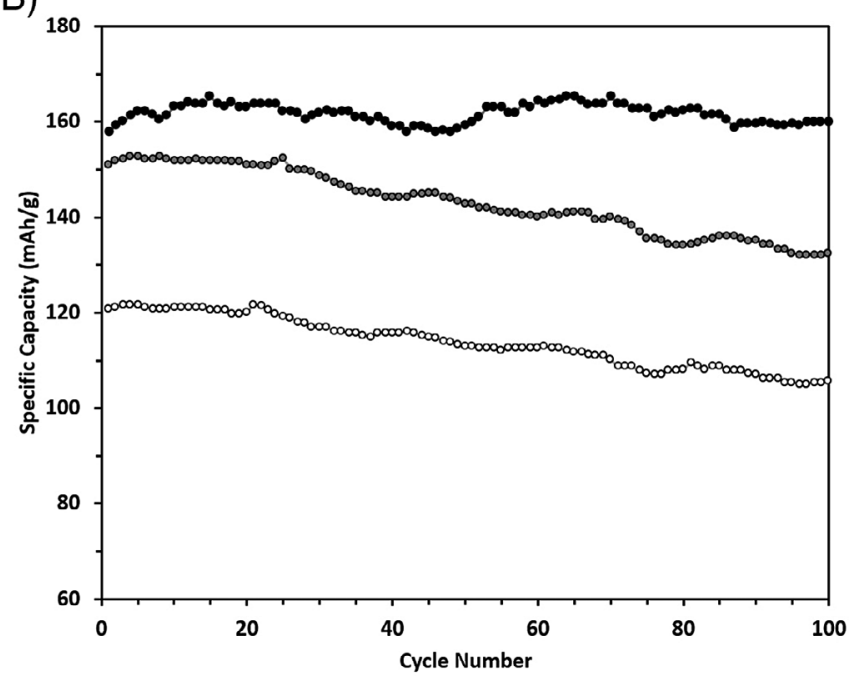

F I G U RE 7 Cycling performance of, A, pristine NCA, and, B, Nafion-coated electrodes (black: 0.1C, gray: 0.5C, white: 1C) 
To get a more in-depth insight into the electrochemical behavior of the electrodes and the effect Nafion coating, we have conducted a systematic analysis with EIS measurements of NCA electrodes before and after cycling tests. In Figure 9, we show the changes in the EIS spectra of the NCA electrodes. The EIS profiles of both cells reveal a semicircle in the high-frequency side and a sloping line in the low-frequency side. At the high-frequency side, the intersection point of the semicircle with the horizontal axis is attributed to the electrolyte impedance. EIS characterization shows that both of the cells had similar ohmic electrolytic resistances before the cycling. ${ }^{79-81}$ The medium-frequency end of the semi-circle is considered as

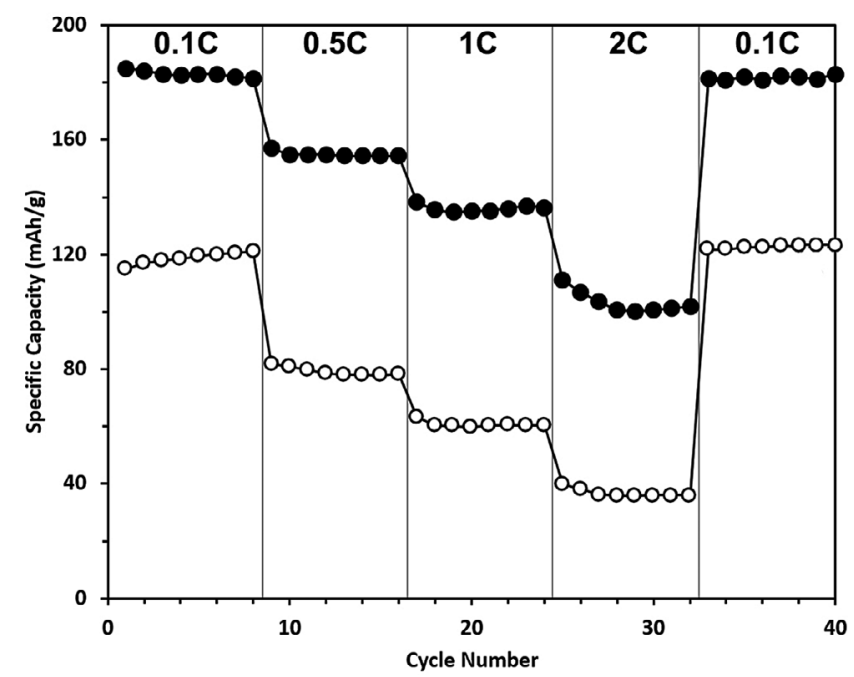

F I G U R E 8 Rate capability performance of NCA electrodes (white: pristine, black: Nafion-coated) the charge transfer resistance. This is the impedance between the cathode and the electrolyte, and it is especially crucial for NCA type cathodes. Even before the cycling, the pristine NCA electrode showed a much higher charge transfer resistance at the electrode/electrolyte interface. The higher charge transfer resistance suggests that already a passive layer had formed on the pristine electrode before cycling due to the side reactions. This finding supports the inferior properties of this electrode, even at the beginning of cycling tests. Nafioncoated NCA electrode provided a natural pathway for $\mathrm{Li}^{+}$ insertion and extraction from the active material to electrolyte and vice versa. ${ }^{82}$ Furthermore, the sloping line at the low-frequency side is the Warburg diffusion region indicating the diffusion in the cathode material. ${ }^{83}$ Since we used the same NCA materials as the cathode, we observed similar trends at the low frequencies.

After 100 cycles at $0.1 \mathrm{C}$, the charge transfer resistance of the pristine NCA electrode significantly increased. We attributed this increase to the degradation of the electrolyte and passive layer formation on the cathode during the side reactions. ${ }^{77,78}$ This charge transfer increase explains the capacity fade of NCA electrodes without any protective coating. However, the Nafion-coated NCA has almost one order of magnitude smaller resistance even after 100 cycles, which depicts the improvement of the charge transfer in the cell. This result is consistent with the stable cycling performance of the Nafion-coated electrodes. The protective conformal coating on the NCA particles, first of all, prevented unwanted reactions like carbonate formation, electrolyte degradation, and spinellike passive layer formation. These unwanted structures decrease the specific capacity, and with cycling cause

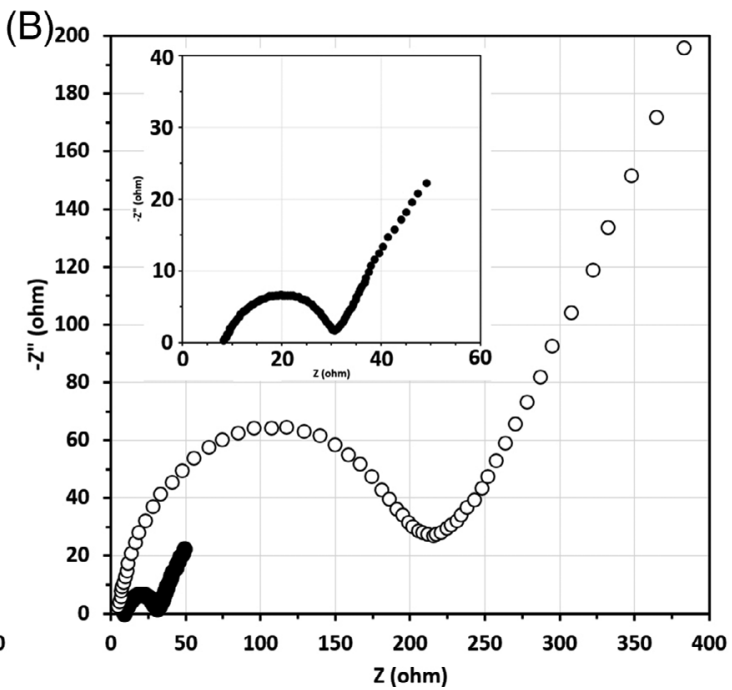

F I G U RE 9 Nyquist plots of pristine and Nafion-coated NCA electrodes, A, before cycling, and, B, after 100 cycles at $0.1 \mathrm{C}$ (white: pristine, black: Nafion-coated) 


\section{Electrolyte Film Cathode}

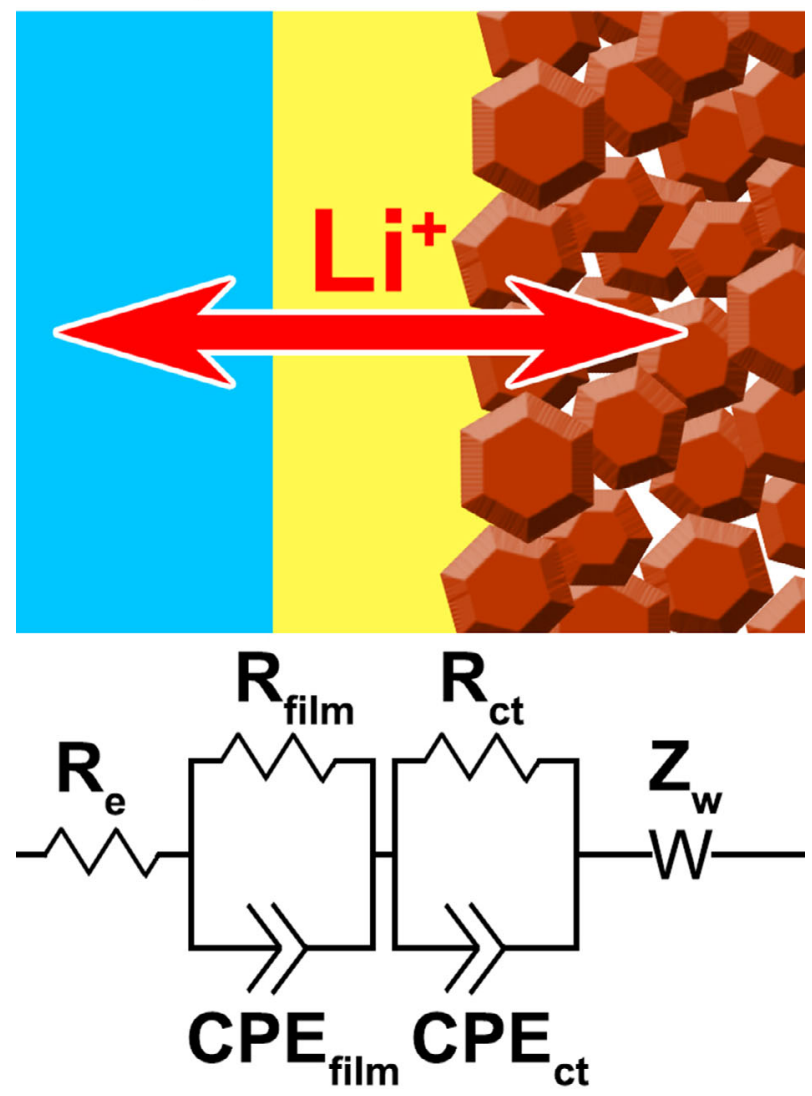

F I G U RE 10 Equivalent circuit and surface structure of the electrode

capacity fading. Nafion coating can effectively prevent the formation of these layers. In addition to that, since Nafion can conduct $\mathrm{Li}^{+}$ions, it does not create extra resistance like passive layers.

To explain the mechanism more in detail, we used the equivalent circuit shown in Figure 10. We assumed that there is a cathode electrolyte interface (CEI) like layer between the electrolyte and the electrode surface. ${ }^{84}$ This film forms an additional impedance for the charge flow. Table 1 presents the fitted values, and Figure S3 shows the related fitting curves. The results show that the electrolyte and charge transfer resistance in the electrode $\left(R_{e}\right.$ and $\left.R_{\mathrm{ct}}\right)$ do not change significantly after 100 cycles. However, the film resistance of the pristine electrode increases almost two times. The film resistance of the Nafion-coated electrode is much lower and even decreases after cycling. The pristine electrode has a high film resistance even before cycling. The high resistance may arise from the formation of a carbonate layer on the untreated NCA surface, which also supports the low initial specific capacity of the pristine electrode.

The suggested mechanism is as follows: The electrolyte adsorbed on the surface can react with the $\mathrm{Ni}^{\mathrm{n}+}$ ions
T A B L E 1 Resistance values of the electrodes before cycling and after 100 cycles

\begin{tabular}{llccl} 
Electrode & & $\boldsymbol{R}_{\boldsymbol{e}}(\boldsymbol{\Omega})$ & $\boldsymbol{R}_{\text {film }}(\boldsymbol{\Omega})$ & $\boldsymbol{R}_{\text {ct }}(\boldsymbol{\Omega})$ \\
\hline Pristine & Before & 4.0 & 81.3 & 48.0 \\
& After & 5.1 & 143.4 & 55.6 \\
\multirow{2}{*}{ Nafion-coated } & Before & 12.1 & 21.6 & 25.7 \\
& After & 5.2 & 3.4 & 20.0 \\
\hline
\end{tabular}

on the cathode surface. During this reaction, electrolyte oxidation occurs, and it starts to deteriorate. The deteriorated components can initiate $\mathrm{Ni}^{\mathrm{n}+}$ leaching, and this results in the cathode material degradation. ${ }^{85}$ All these materials formed in the electrolyte can lead to CEI, which is composed of $-\left(\mathrm{CF}_{2}\right)_{\mathrm{n}^{-}}$and $\mathrm{NiF}_{2}{ }^{86}$ This CEI is an insulating material and creates an additional resistance on the electrode surface. Without a protective layer, due to the cracks formed, the CEI layer grows; thus, the electrolyte continues to degrade, and the resistance increases more. Eventually, this results in a capacity fading. When a Nafion layer is present on the cathode surface, it prevents the direct contact of the electrolyte and $\mathrm{Ni}^{\mathrm{n}+}$ ions. As a result, no CEI forms. Initially, since the Nafion is not lithiated, an additional resistance occurs in the first cycle. However, after the first cycle, this resistance drops since the Nafion becomes lithiated.

\section{I CONCLUSION}

In this research, $\mathrm{LiNi}_{0.80} \mathrm{Co}_{0.15} \mathrm{Al}_{0.05} \mathrm{O}_{2}$ (NCA) material was synthesized by a co-precipitation method with oxalic acid. The prepared electrodes were coated with Nafion to have a conformal layer on the NCA nanoparticles against side reactions. The Nafion coating both prevented the side reactions and facilitated the $\mathrm{Li}^{+}$ movement between the electrode and electrolyte. Due to the protective coating, the electrode did show any capacity fading after 100 cycles. Without any protective layer, the electrode structure degrades, a passive layer forms, and the electrode starts to fail. The modified surface of NCA with high ionic conductivity provides an optimal material for long cycling. More importantly, the ease of coating NCA with an ion-conductive protective layer makes the process suitable for industrial manufacturing.

\section{ORCID}

Selmiye Alkan Gürsel (1D https://orcid.org/0000-0002-79666352

Alp Yürüm (1) https://orcid.org/0000-0002-1284-3924 


\section{REFERENCES}

1. Daniel C, Mohanty D, Li JL, Wood DL. Cathode materials review. AIP Conf Proc. 2014;1597:26-43.

2. Winter M, Besenhard JO. Rechargeable batteries. Chem Unserer Zeit. 1999;33:320-332.

3. Osiak M, Geaney H, Armstrong E, O'Dwyer C. Structuring materials for lithium-ion batteries: advancements in nanomaterial structure, composition, and defined assembly on cell performance. J Mater Chem A. 2014;2:9433-9460.

4. Goodenough JB, Kim Y. Challenges for rechargeable Li batteries. Chem Mater. 2010;22:587-603.

5. Nitta N, Wu FX, Lee JT, Yushin G. Li-ion battery materials: present and future. Mater Today. 2015;18:252-264.

6. Nair NKC, Garimella N. Battery energy storage systems: assessment for small-scale renewable energy integration. Energ Buildings. 2010;42:2124-2130.

7. Ellis BL, Lee KT, Nazar LF. Positive electrode materials for Liion and Li-batteries. Chem Mater. 2010;22:691-714.

8. Brandt K. Historical development of secondary lithium batteries. Solid State Ion. 1994;69:173-183.

9. Chen CF, Barai P, Mukherjee PP. An overview of degradation phenomena modeling in lithium-ion battery electrodes. Curr Opin Chem Eng. 2016;13:82-90.

10. Leifer N, Srur-Lavi O, Matlahov I, Markovsky B, Aurbach D, Goobes G. $\mathrm{LiNi}_{0.8} \mathrm{Co}_{0.15} \mathrm{Al}_{0.05} \mathrm{O}_{2}$ cathode material: new insights via Li-7 and Al-27 magic-angle spinning NMR spectroscopy. Chem Mater. 2016;28:7594-7604.

11. Liu ZH, Wang Z, Lu TZ, Dai PP, Gao P, Zhu YM. Modification of $\mathrm{LiNi}_{0.8} \mathrm{Co}_{0.15} \mathrm{Al}_{0.05} \mathrm{O}_{2}$ using nanoscale carbon coating. J Alloy Compd. 2018;763:701-710.

12. Kim Y, Kim D. Synthesis of high-density nickel cobalt aluminum hydroxide by continuous Coprecipitation method. Acs Appl Mater Inter. 2012;4:586-589.

13. Li DC, Yuan CQ, Dong JQ, Peng ZH, Zhou YH. Synthesis and electrochemical properties of $\mathrm{LiNi}_{0.85-\mathrm{x}} \mathrm{Co}_{\mathrm{x}} \mathrm{Mn}_{0.15} \mathrm{O}_{2}$ as cathode materials for lithium-ion batteries. J Solid State Electr. 2008;12: 323-327.

14. Adelhelm P, Armbruster M, Kraus F. Solid-state chemistry 2012. Nachr Chem. 2013;61:252-264.

15. Broussely M, Archdale G. Li-ion batteries and portable power source prospects for the next 5-10 years. J Power Sources. 2004; 136:386-394.

16. Schmidt T, Buchert M, Schebek L. Investigation of the primary production routes of nickel and cobalt products used for Li-ion batteries. Resour Conserv Recy. 2016;112:107-122.

17. Senna M. Solid state mechanochemical processes for better electroceramics. Acta Chim Slov. 2014;61:425-431.

18. Xu J, Lin F, Doeff MM, Tong W. A review of Ni-based layered oxides for rechargeable Li-ion batteries. J Mater Chem A. 2017; 5:874-901.

19. Purwanto A, Yudha CS, Ubaidillah U, Widiyandari H, Ogi T, Haerudin H. NCA cathode material: synthesis methods and performance enhancement efforts. Mater Res Express. 2018;5:122001.

20. Ju SH, Kim JH, Kang YC. Electrochemical properties of LiN$\mathrm{i}_{0.8} \mathrm{Co}_{0.2-\mathrm{x}} \mathrm{Al}_{\mathrm{x}} \mathrm{O}_{2}(0<=\mathrm{x}<=0.1)$ cathode particles prepared by spray pyrolysis from the spray solutions with and without organic additives. Met Mater Int. 2010;16:299-303.

21. Goodenough JB. Cathode materials: a personal perspective. J Power Sources. 2007;174:996-1000.
22. Fischer J, Chang K, Ye J, et al. Structural transformation of sputtered o- $\mathrm{LiMnO}_{2}$ thin-film cathodes induced by electrochemical cycling. Thin Solid Films. 2013;549:263-267.

23. Jang YI, Huang BY, Wang HF, Sadoway DR, Chiang YM. Electrochemical cycling-induced spinel formation in high-chargecapacity orthorhombic $\mathrm{LiMnO}_{2}$. J Electrochem Soc. 1999;146: 3217-3223.

24. Zhu CY, Han K, Geng DS, Ye HQ, Meng XB. Achieving highperformance silicon anodes of lithium-ion batteries via atomic and molecular layer deposited surface coatings: an overview. Electrochim Acta. 2017;251:710-728.

25. Meng $\mathrm{FB}$, Guo $\mathrm{HJ}$, Wang $\mathrm{ZX}$, et al. Modification of $\mathrm{Li}$ $\left[\mathrm{Li}_{0.2} \mathrm{Mn}_{0.54} \mathrm{Ni}_{0.13} \mathrm{Co}_{0.13}\right] \mathrm{O}_{2}$ cathode with alpha- $\mathrm{MoO}_{3}$ via a simple wet chemical coating process. Appl Surf Sci. 2019;479:12771286.

26. Zheng J-C, Yang Z, He Z-J, Tong H, Yu W-J, Zhang J-F. In situ formed $\mathrm{LiNi}_{0.8} \mathrm{Co}_{0.15} \mathrm{Al}_{0.05} \mathrm{O}_{2} @ \mathrm{Li}_{4} \mathrm{SiO}_{4}$ composite cathode material with high rate capability and long cycling stability for lithium-ion batteries. Nano Energy. 2018;53:613-621.

27. Liu Y, Tang L-b, Wei H-x, Zhang X-h, He Z-j, Li Y-j, Zheng J-c. Enhancement on structural stabilityof Ni-rich cathode materials by in-situ fabricating dual-modified layer forlithium-ion batteries. Nano Energy. 2019;65:104043.

28. Zheng J, Yang Z, Dai A, Tang L, Wei H, Li Y, He Z, Lu J. Boosting cell performance of $\mathrm{LiNi}_{0.8} \mathrm{Co}_{0.15} \mathrm{Al}_{0.05} \mathrm{O}_{2}$ via surface structure design. Small. 2019;15-50:1904854.

29. Chung Y, Ryu SH, Ju JH, et al. A surfactant-based method for carbon coating of $\mathrm{LiNi}_{0.8} \mathrm{Co}_{0.15} \mathrm{Al}_{0.05} \mathrm{O}_{2}$ cathode in $\mathrm{Li}$ ion batteries. B Korean Chem Soc. 2010;31:2304-2308.

30. Winter M, Brodd RJ. What are batteries, fuel cells, and supercapacitors? (vol 104, pg 4245, 2003). Chem Rev. 2005;105:1021-1021.

31. Kim Y. Encapsulation of LiNi0.5Co0.2Mn0.3O2 with a thin inorganic electrolyte film to reduce gas evolution in the application of lithium ion batteries. Phys Chem Chem Phys. 2013;15: 6400-6405.

32. Esmaeili N, Gray EM, Webb CJ. Non-fluorinated polymer composite proton exchange membranes for fuel cell applications-a review. ChemPhysChem. 2019;20:2016-2053.

33. Ohzuku T, Ueda A, Nagayama M. Electrochemistry and structural chemistry of $\mathrm{LiNiO}_{2}$ (R[3]over-bar-M) for 4 volt secondary lithium cells. J Electrochem Soc. 1993;140:1862-1870.

34. Wulff H, Rao MM, Scholz F. Crystallographic evidence for the formation of a continuous series of mixed crystals between $\mathrm{NiO}$ and $\mathrm{LiNiO}_{2}$. Chem Mater. 2003;15:988-993.

35. Robert R, Villevieille C, Novak P. Enhancement of the high potential specific charge in layered electrode materials for lithium-ion batteries. J Mater Chem A. 2014;2:8589-8598.

36. Gabrisch H, Yazami R, Fultz B. The character of dislocations in $\mathrm{LiCoO}_{2}$. Electrochem Solid State Lett. 2002;5:A111-A114.

37. Chen YJ, Li P, Zhao SJ, et al. Influence of integrated microstructure on the performance of $\mathrm{LiN}_{\mathrm{i} 0.8} \mathrm{Co}_{0.15} \mathrm{Al}_{0.05} \mathrm{O}_{2}$ as a cathodic material for lithium ion batteries. RSC Adv. 2017;7: 29233-29239.

38. Song $\mathrm{CH}$, Wang WG, Peng $\mathrm{HL}$, et al. Improving the electrochemical performance of $\mathrm{LiNi}_{0.80} \mathrm{Co}_{0.15} \mathrm{Al}_{0.05} \mathrm{O}_{2}$ in lithium ion batteries by $\mathrm{LiAlO}_{2}$ surface modification. Appl Sci Basel. 2018; 8:378.

39. Muzayanha SU, Yudha CS, Nur A, et al. A fast metals recovery method for the synthesis of lithium nickel cobalt 
aluminum oxide material from cathode waste. Metals Basel. 2019;9:615.

40. Li HY, Li J, Zaker N, Zhang N, Botton GA, Dahn JR. Synthesis of single crystal $\mathrm{LiNi}_{0.88} \mathrm{Co}_{0.09} \mathrm{Al}_{0.03} \mathrm{O}_{2}$ with a two-step Lithiation method. J Electrochem Soc. 2019;166:A1956-A1963.

41. Li J, Zhang N, Li HY, et al. Impact of the synthesis conditions on the performance of $\mathrm{LiNi}_{\mathrm{x}} \mathrm{Co}_{\mathrm{y}} \mathrm{Al}_{\mathrm{z}} \mathrm{O}_{2}$ with high $\mathrm{Ni}$ and low co content. J Electrochem Soc. 2018;165:A3544-A3557.

42. Kim J, Amine K. A comparative study on the substitution of divalent, trivalent and tetravalent metal ions in $\mathrm{LiNi}_{1-\mathrm{x}} \mathrm{M}_{\mathrm{x}} \mathrm{O}_{2}$ $\left(\mathrm{M}=\mathrm{Cu}^{2+}, \mathrm{Al}^{3+}\right.$ and $\left.\mathrm{Ti}^{4+}\right)$. J Power Sources. 2002;104:33-39.

43. Zhu XJ, Liu HX, Gan XY, et al. Preparation and characterization of $\mathrm{LiNi}_{0.80} \mathrm{Co}_{0.20-\mathrm{x}} \mathrm{Al}_{\mathrm{x}} \mathrm{O}_{2}$ as cathode materials for lithium ion batteries. $J$ Electroceram. 2006;17:645-649.

44. Xia SB, Zhang YJ, Dong P, Zhang YN. Synthesis cathode material $\mathrm{LiNi}_{0.80} \mathrm{Co}_{0.15} \mathrm{Al}_{0.05} \mathrm{O}_{2}$ with two step solid-state method under air stream. Eur Phys J Appl Phys. 2014;65:10401.

45. Radin MD, Hy S, Sina M, et al. Narrowing the gap between theoretical and practical capacities in Li-ion layered oxide cathode materials. Adv Energy Mater. 2017;7:1602888.

46. Majumder SB, Nieto S, Katiyar RS. Synthesis and electrochemical properties of $\mathrm{LiNi}_{0.80}\left(\mathrm{Co}_{0.20-\mathrm{x}} \mathrm{Al}_{\mathrm{x}}\right) \mathrm{O}_{2}(\mathrm{x}=0.0$ and 0.05$)$ cathodes for Li ion rechargeable batteries. J Power Sources. 2006; 154:262-267.

47. Qiu ZP, Zhang YJ, Dong P, Wang D, Xia SB. A ternary oxide precursor with trigonal structure for synthesis of $\mathrm{LiN}$ $\mathrm{i}_{0.80} \mathrm{Co}_{0.15} \mathrm{Al}_{0.05} \mathrm{O}_{2}$ cathode material. J Solid State Electr. 2017; 21:3037-3046.

48. Qiu ZP, Zhang YJ, Dong P, Xia SB, Yao Y. A facile method for synthesis of $\mathrm{LiNi}_{0.8} \mathrm{Co}_{0.15} \mathrm{Al}_{0.05} \mathrm{O}_{2}$ cathode material. Solid State Ion. 2017;307:73-78.

49. Grenier A, Liu H, Wiaderek KM, et al. Reaction heterogeneity in $\mathrm{LiNi}_{0.8} \mathrm{Co}_{0.15} \mathrm{Al}_{0.05} \mathrm{O}_{2}$ induced by surface layer. Chem Mater. 2017;29:7345-7352.

50. Zhao TL, Ji RX, Meng Y. The role of precipitant in the preparation of lithium-rich manganese-based cathode materials. Chem Phys Lett. 2019;730:354-360.

51. Li YS, Wang J, Zhou ZF, et al. $\mathrm{LiNi}_{0.5} \mathrm{Mn}_{1.5} \mathrm{O}_{4}$ porous microcubes synthesized by a facile oxalic acid co-precipitation method as cathode materials for lithium-ion batteries. Int $J$ Electrochem Sc. 2019;14:2822-2832.

52. Tebbe JL, Holder AM, Musgrave CB. Mechanisms of $\mathrm{LiCoO}_{2}$ cathode degradation by reaction with $\mathrm{HF}$ and protection by thin oxide coatings. Acs Appl Mater Inter. 2015;7:24265-24278.

53. Jung SK, Gwon $\mathrm{H}$, Hong J, et al. Understanding the degradation mechanisms of $\mathrm{LiNi}_{0.5} \mathrm{Co}_{0.2} \mathrm{Mn}_{0.3} \mathrm{O}_{2}$ cathode material in lithium ion batteries. Adv Energy Mater. 2014;4:1300787.

54. Hao SQ, Wolverton C. Lithium transport in amorphous $\mathrm{Al}_{2} \mathrm{O}_{3}$ and AlF3 for discovery of battery coatings. J Phys Chem C. 2013;117:8009-8013.

55. Li C, Zhang HP, Fu LJ, et al. Cathode materials modified by surface coating for lithium ion batteries. Electrochim Acta. 2006;51:3872-3883.

56. Zuo DX, Tian GL, Li X, Chen D, Shu KY. Recent progress in surface coating of cathode materials for lithium ion secondary batteries. J Alloy Compd. 2017;706:24-40.

57. Cho Y, Cho J. Significant improvement of $\mathrm{LiNi}_{0.8} \mathrm{Co}_{0.15} \mathrm{Al}_{0.05} \mathrm{O}_{2}$ cathodes at 60 degrees $\mathrm{C}$ by $\mathrm{SiO}_{2}$ dry coating for Li-ion batteries. J Electrochem Soc. 2010;157:A625-A629.
58. Mohanty D, Dahlberg K, King DM, et al. Modification of Nirich FCG NMC and NCA cathodes by atomic layer deposition: preventing surface phase transitions for high-voltage lithiumion batteries. Sci Rep UK. 2016;6:26532.

59. Srur-Lavi O, Miikkulainen V, Markovsky B, et al. Studies of the electrochemical behavior of $\mathrm{LiNi}_{0.80} \mathrm{Co}_{0.15} \mathrm{Al}_{0.05} \mathrm{O}_{2}$ electrodes coated with $\mathrm{LiAlO}_{2}$. J Electrochem Soc. 2017;164:A3266A3275.

60. Laskar MR, Jackson DHK, Guan YX, et al. Atomic layer deposition of $\mathrm{Al} 2 \mathrm{O} 3-\mathrm{Ga} 2 \mathrm{O} 3$ alloy coatings for $\mathrm{Li}\left[\mathrm{Ni}_{0.5} \mathrm{Mn}_{0.3} \mathrm{Co}_{0.2}\right] \mathrm{O}_{2}$ cathode to improve rate performance in Li-ion battery. Acs Appl Mater Inter. 2016;8:10572-10580.

61. Park TJ, Lim JB, Son JT. Effect of calcination temperature of size controlled microstructure of $\mathrm{LiNi}_{0.8} \mathrm{Co}_{0.15} \mathrm{Al}_{0.05} \mathrm{O}_{2}$ cathode for rechargeable lithium battery. B Korean Chem Soc. 2014;35: 357-364.

62. Tran HY, Greco G, Taubert C, Wohlfahrt-Mehrens M, Haselrieder W, Kwade A. Influence of electrode preparation on the electrochemical performance of LiNi0.8Co0.15Al0.05O2 composite electrodes for lithium-ion batteries. J Power Sources. 2012;210:276-285.

63. Liu BS, Wang ZB, Yu FD, et al. Facile strategy of NCA cation mixing regulation and its effect on electrochemical performance. RSC Adv. 2016;6:108558-108565.

64. Chen $\mathrm{C}, \mathrm{Xu} \mathrm{M}$, Zhang K, et al. Atomically ordered and epitaxially grown surface structure in core-shell $\mathrm{NCA} / \mathrm{NiAl}_{2} \mathrm{O}_{4}$ enabling high voltage cyclic stability for cathode application. Electrochim Acta. 2019;300:437-444.

65. Wang QS, Mao BB, Stoliarov SI, Sun JH. A review of lithium ion battery failure mechanisms and fire prevention strategies. Prog Energ Combust. 2019;73:95-131.

66. Zhou HM, Yang ZH, Xiao DM, Xiao KW, Li J. An electrolyte to improve the deep charge-discharge performance of LiN$\mathrm{i}_{0.8} \mathrm{Co}_{0.15} \mathrm{Al}_{0.05} \mathrm{O}_{2}$ cathode. J Mater Sci Mater El. 2018;29:66486659.

67. Li Y, Lai FY, Zhang XH, et al. Surface modification of Sr-doped $\mathrm{LaMnO}_{3}$ coating by spray drying on Ni-rich LiN$\mathrm{i}_{0.8} \mathrm{Mn}_{0.1} \mathrm{Co}_{0.1} \mathrm{O}_{2}$ cathode material for lithium-ion batteries. J Taiwan Inst Chem E. 2019;102:225-232.

68. Van der Ven A, Garikipati K, Kim S, Wagemaker M. The role of coherency strains on phase stability in $\mathrm{Li}_{x} \mathrm{FePO}_{4}$ : needle crystallites minimize coherency strain and overpotential. J Electrochem Soc. 2009;156:A949-A957.

69. Makimura Y, Sasaki T, Nonaka $\mathrm{T}$, et al. Factors affecting cycling life of $\mathrm{LiNi}_{0.8} \mathrm{Co}_{0.15} \mathrm{Al}_{0.05} \mathrm{O}_{2}$ for lithium-ion batteries. J Mater Chem A. 2016;4:8350-8358.

70. Waldmann T, Kasper M, Wohlfahrt-Mehrens M. Optimization of charging strategy by prevention of lithium deposition on anodes in high-energy lithium-ion batteries--electrochemical experiments. Electrochim Acta. 2015;178:525-532.

71. Watanabe S, Kinoshita M, Hosokawa T, Morigaki K, Nakura K. Capacity fading of $\mathrm{LiAl}_{\mathrm{y}} \mathrm{Ni}_{1-\mathrm{x}-\mathrm{y}} \mathrm{Co}_{\mathrm{x}} \mathrm{O}_{2}$ cathode for lithium-ion batteries during accelerated calendar and cycle life tests (effect of depth of discharge in charge-discharge cycling on the suppression of the micro-crack generation of $\mathrm{LiAl}_{\mathrm{y}} \mathrm{Ni}_{1-\mathrm{x}}$ ${ }_{\mathrm{y}} \mathrm{Co}_{\mathrm{x}} \mathrm{O}_{2}$ particle). J Power Sources. 2014;260:50-56.

72. Park KJ, Hwang JY, Ryu HH, et al. Degradation mechanism of Ni-enriched NCA cathode for lithium batteries: are microcracks really critical? ACS Energy Lett. 2019;4:1394-1400. 
73. Lin F, Markus IM, Nordlund D, et al. Surface reconstruction and chemical evolution of stoichiometric layered cathode materials for lithium-ion batteries. Nat Commun. 2014;5:3529.

74. Kim Y, Cho J. Lithium-reactive $\mathrm{Co}_{3}\left(\mathrm{PO}_{4}\right)_{2}$ nanoparticle coating on high-capacity $\mathrm{LiNi}_{0.8} \mathrm{Co}_{0.16} \mathrm{Al}_{0.04} \mathrm{O}_{2}$ cathode material for lithium rechargeable batteries. J Electrochem Soc. 2007;154:A495A499.

75. Lee DJ, Scrosati B, Sun YK. $\mathrm{Ni}_{3}\left(\mathrm{PO}_{4}\right)_{2}$-coated Li $\left[\mathrm{Ni}_{0.8} \mathrm{Co}_{0.15} \mathrm{Al}_{0.05}\right] \mathrm{O}_{2}$ lithium battery electrode with improved cycling performance at 55 degrees C. J Power Sources. 2011;196: 7742-7746.

76. Xu Y, Li XH, Wang ZX, Guo HJ, Huang B. Structure and electrochemical performance of $\mathrm{TiO}_{2}$-coated $\mathrm{LiNi}_{0.80} \mathrm{CO}_{0.15} \mathrm{Al}_{0.05} \mathrm{O}_{2}$ cathode material. Mater Lett. 2015;143:151-154.

77. Jo E, Hwang S, Kim SM, Chang W. Investigating the kinetic effect on structural evolution of $\mathrm{Li}_{\mathrm{x}} \mathrm{Ni}_{0.8} \mathrm{Co}_{0.15} \mathrm{Al}_{0.05} \mathrm{O}_{2}$ cathode materials during the initial charge/discharge. Chem Mater. 2017;29:2708-2716.

78. Zhang HL, Karki K, Huang YQ, Whittingham MS, Stach EA, Zhou GW. Atomic insight into the layered/spinel phase transformation in charged $\mathrm{LiNi}_{0.80} \mathrm{Co}_{0.15} \mathrm{Al}_{0.05} \mathrm{O}_{2}$ cathode particles. J Phys Chem C. 2017;121:1421-1430.

79. Shenouda AY, Momchilov AA. A study on graphene/tin oxide performance as negative electrode compound for lithium battery application. J Mater Sci-Mater El. 2019;30:79-90.

80. Eliseeva SN, Apraksin RV, Tolstopjatova EG, Kondratiev VV. Electrochemical impedance spectroscopy characterization of LiFePO4 cathode material with carboxymethylcellulose and poly-3,4-ethylendioxythiophene/polystyrene sulfonate. Electrochim Acta. 2017;227:357-366.

81. Gantenbein S, Weiss M, Ivers-Tiffee E. Impedance based timedomain modeling of lithium-ion batteries: part I. J Power Sources. 2018;379:317-327.
82. Yuan H, Song WB, Wang M, Gu YJ, Chen YB. Lithium-ion conductive coating layer on nickel rich layered oxide cathode material with improved electrochemical properties for Li-ion battery. J Alloy Compd. 2019;784:1311-1322.

83. Rubinson JF, Kayinamura YP. Charge transport in conducting polymers: insights from impedance spectroscopy. Chem Soc Rev. 2009;38:3339-3347.

84. Zhang H, Yang J, Hou H, Chen S, Yao H. Nitrogen-doped carbon paper with $3 \mathrm{D}$ porous structure as a flexible free-standing anode for lithium-ion batteries. Sci Rep. 2017;7:7769.

85. Jarry A, Gottis S, Yu Y-S, et al. The formation mechanism of fluorescent metal complexes at the $\mathrm{Li}_{\mathrm{x}} \mathrm{Ni}_{0.5} \mathrm{Mn}_{1.5} \mathrm{O}_{4-\delta} /$ carbonate ester electrolyte Interface. J Am Chem Soc. 2015;137:35333539.

86. Han J-G, Lee JB, Cha A, et al. Unsymmetrical fluorinated malonatoborate as an amphoteric additive for high-energy-density, lithium-ion batteries. Energ Environ Sci. 2018;11:1552-1562.

\section{SUPPORTING INFORMATION}

Additional supporting information may be found online in the Supporting Information section at the end of this article.

How to cite this article: Yiğitalp A, Taşdemir A, Alkan Gürsel S, Yürüm A. Nafion-coated $\mathrm{LiNi}_{0.80} \mathrm{Co}_{0.15} \mathrm{Al}_{0.05} \mathrm{O}_{2}$ (NCA) cathode preparation and its influence on the Li-ion battery cycle performance. Energy Storage. 2020;e154. https:// doi.org/10.1002/est2.154 